\title{
Depósitos tecnogênicos como testemunhos e indicadores de processos geológicos em área urbana degradada em Guarulhos, SP
}

\section{Technogenic deposits as witnesses and indicators of geological processes in urban area degraded in Guarulhos, SP}

\author{
Adriana Aparecida de Oliveira ${ }^{\mathrm{ab}}$, Antonio Manoel dos Santos Oliveira ${ }^{\mathrm{ac}}$, Marcio Roberto \\ Magalhães Andrade ${ }^{\text {ad }}$ \\ ${ }^{\mathrm{a}}$ Universidade de Guarulhos \\ breinadriana@gmail.com, caoliveira@prof.ung.br, ${ }^{\mathrm{d}}$ mmandrade@prof.ung.br
}

\begin{abstract}
RESUMO
Este trabalho visa apresentar depósitos tecnogênicos como testemunhos e indicadores de ações antrópicas de urbanização, utilizando a implantação de loteamento no município de Guarulhos (SP) como estudo de caso. A região objeto de estudo possui área degradada que foi terraplenada, porém embargada pela prefeitura e posteriormente abandonada. Os processos de erosão e assoreamento que se manifestaram produziram os referidos depósitos. Este estudo foi conduzido pela abordagem geotecnogênica, que considera o homem como agente geológico com relevância para a caracterização de depósitos tecnogênicos. A situação atual dos depósitos indica tendência à estabilização dos processos, e suas camadas testemunham a história dinâmica de tais processos.
\end{abstract}

Palavras-chave: Depósitos tecnogênicos; Microbacia urbana; Abordagem geotecnogênica; Guarulhos.

\begin{abstract}
This work aims to present technogenic deposits as testimony and indicators of anthropogenic actions of urbanization using the deployment of allotment in Guarulhos (SP) as a case study. The study object region has some degraded area where there was earthwork, however, an embargo was imposed by the City hall, and the area was subsequently abandoned. The manifested processes of erosion and sedimentation caused such deposits. This study was conducted through geotechnogenic approach which considers Man as a geological agent and it is relevant to the characterization of tecnogenic deposits. The current situation of the deposits indicates tendency for the stabilization of the processes and their layers testify to the dynamic history of such processes, since the area had some earthwork done.
\end{abstract}

Keywords: Technogenic deposits; Urban watershed; Geotechnogenic approach; Guarulhos.

\section{Introdução}

No mundo científico vêm sendo consideradas as magnitudes das ações antrópicas que, projetadas para os milhões de anos dos períodos geológicos, atualmente ultrapassam as taxas naturais de movimentos de terra, conforme Wilkinson (2005).

O papel do homem como o mais novo e intenso agente geológico na transformação do planeta está sendo destacado de tal forma que Ter-Stepanian (1988) sugeriu uma nova época, o Tecnógeno, e o Antropoceno foi sugerido por Crutzen \& Stoermer (2000).

A ação antrópica deixa sua marca na superfície terrestre, seja na forma direta dos processos tecnológicos como terraplenagens e construções, seja indiretamente por cicatrizes de processos de degradação, como escorregamentos e erosões, induzidos pelo uso da terra, seja ainda como agradação, nos fundos dos vales, por depósitos correlatos das degradações. Estes depósitos, denominados tecnogênicos, conforme Chemekov (1983), constituem testemunhos das ações antrópicas, como as formações geológicas testemunham os períodos geológicos. Tais depósitos também são úteis como indicadores do estado em que se encontram tais processos.

Guarulhos, como a Região Metropolitana de São Paulo - RMSP, vem sofrendo um processo extremamente dinâmico de expansão urbana, pressionando a ocupação de áreas frágeis sob o ponto de vista geoambiental.

Entre essas áreas destacam-se as de relevo de morros, sobretudo quando submetidas a intensos movimentos de terra para implantação de loteamentos. Uma delas 
Antropoceno - Tecnógeno

corresponde a uma gleba embargada pela prefeitura de Guarulhos, adjacente ao loteamento do Parque Continental II, que foi abandonada como solo exposto, após a intensa terraplenagem realizada, podendo ser considerada como um caso de expansão urbana da RMSP, conforme estudos anteriores de Andrade (1999, 2009) e Oliveira et al. (2009). De fato, foram realizadas grandes movimentações de terra em área de morro para a construção de amplas superfícies de aterro e corte, visando ampliar as quadras e lotes a serem vendidos. Como consequência, observou-se uma série de problemas geotécnicos, resultando num quadro de degradação ambiental, especialmente em decorrência de processos de erosão e assoreamento, que formaram os depósitos tecnogênicos.

Este quadro reflete a transformação urbana, considerada das mais intensas provocadas pelo homem como agente geológico, resultando na criação de áreas artificiais, depósitos tecnogênicos como assoreamento e processos correlatos de erosão e escorregamento denominados antrópicos ou geotecnogênicos segundo, Oliveira (1990) e Peloggia (1998).

\section{Objetivos}

O principal objetivo deste trabalho é apresentar os depósitos tecnogênicos como testemunhos e indicadores de ações antrópicas numa microbacia urbana, utilizando uma área degradada como estudo de caso. Este objetivo indica a adoção da abordagem geotecnogênica da transformação geoambiental provocada pela urbanização.

\section{3. Área objeto de estudo}

A escolha da área objeto de estudo foi orientada pelo conhecimento prévio da área em estudos anteriores (Oliveira et al. 2009) e seus processos de erosão e assoreamento, resultantes da terraplenagem realizada.

A área de estudo situa-se no município de Guarulhos, Região Metropolitana de São Paulo - RMSP apresentada na figura 1.

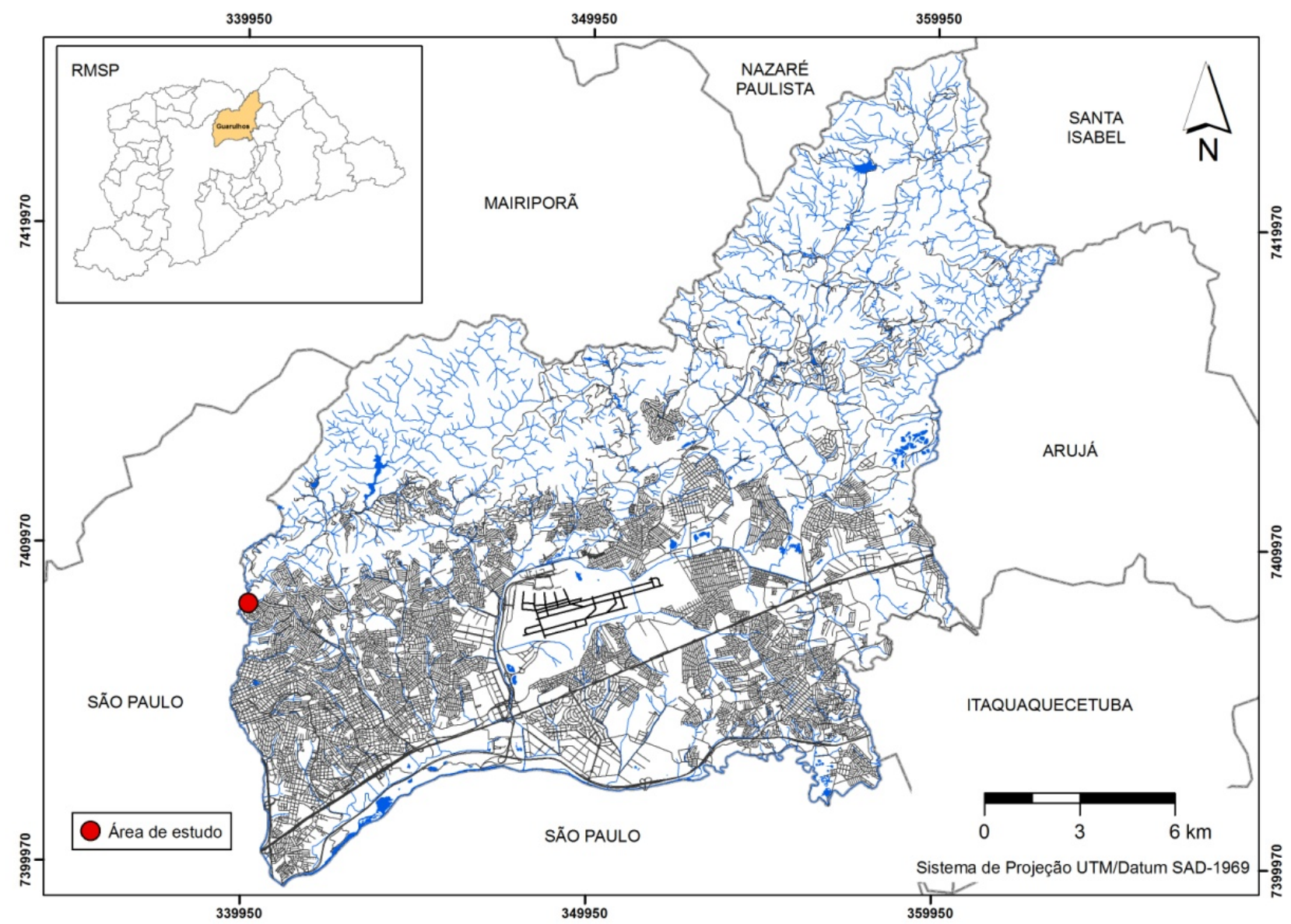

Figura 1: Localização da área de estudo em Guarulhos, Região Metropolitana de São Paulo (Fonte: Laboratório de Geoprocessamento - UnG)

A figura 2 apresenta foto aérea recente (2009) com as delimitações da microbacia englobando os loteamentos Jardim Palmira, Parque Continental II e área degradada gerada por terraplenagem e posteriormente abandonada. 


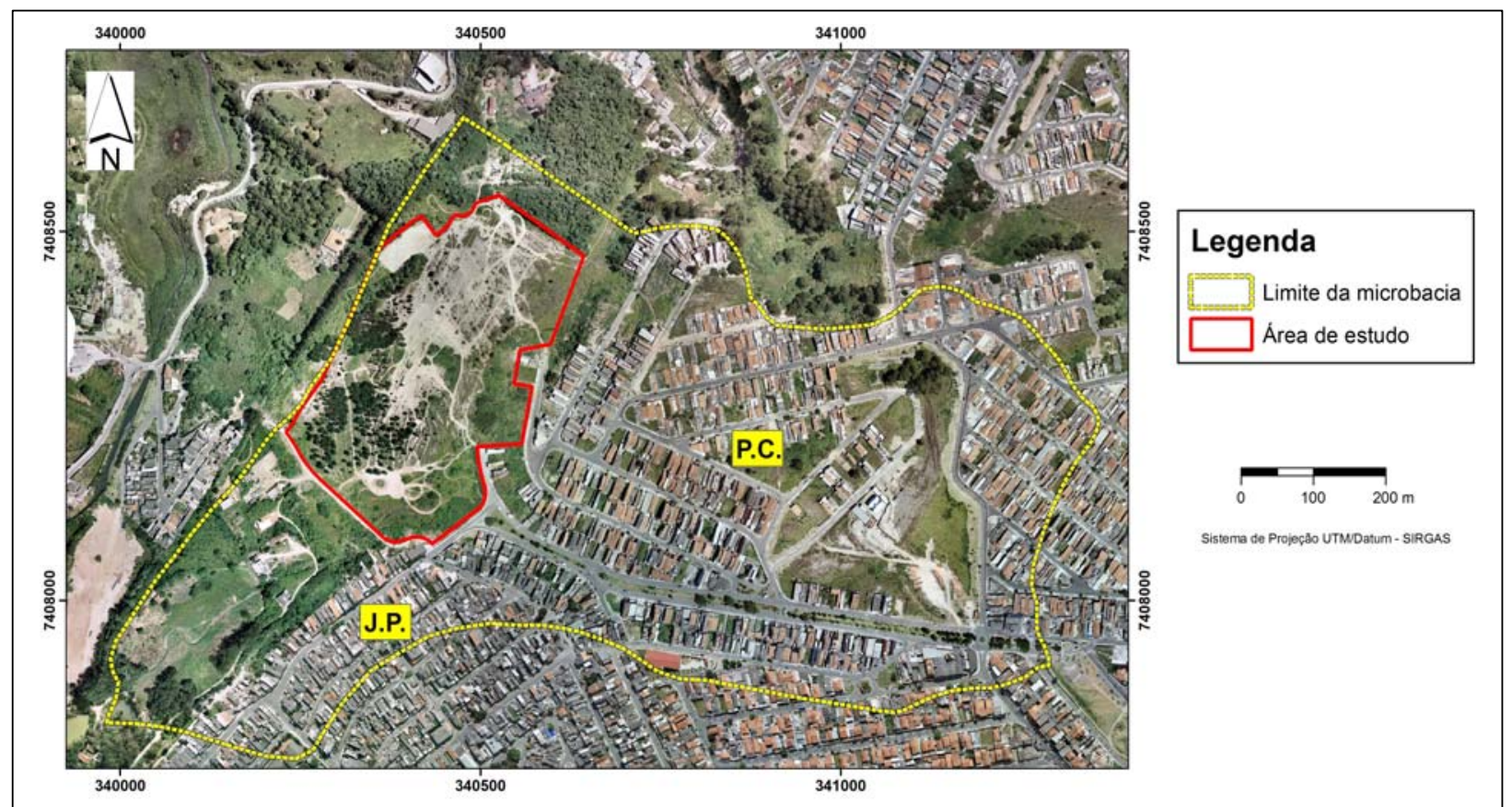

Figura 2: Microbacia objeto de estudo, área degradada e os loteamentos do Parque Continental II (P.C.) e Jardim Palmira (J.P.). Base: Imagem P.M.G. (2009

\section{Materiais e métodos}

A abordagem metodológica tem como fundamentos a Geologia Aplicada ao Meio Ambiente e a Engenharia Civil, ou Geologia de Engenharia, e os métodos são baseados na Cartografia Geotécnica envolvendo fotointerpretação, medição gráfica em cartas topográficas e levantamentos de campo para o reconhecimento de fatores condicionantes dos processos geodinâmicos. Esta abordagem foi aplicada referenciando-se no homem como agente geológico, que fundamenta o estudo do Tecnógeno, conforme proposto por Ter-Stepanian (1988) no campo da Geologia de Engenharia, ou seja, uma abordagem geotecnogênica.

Para que sejam alcançados os objetivos do trabalho, foram desenvolvidas as etapas apresentadas a seguir, no fluxograma da figura 3.

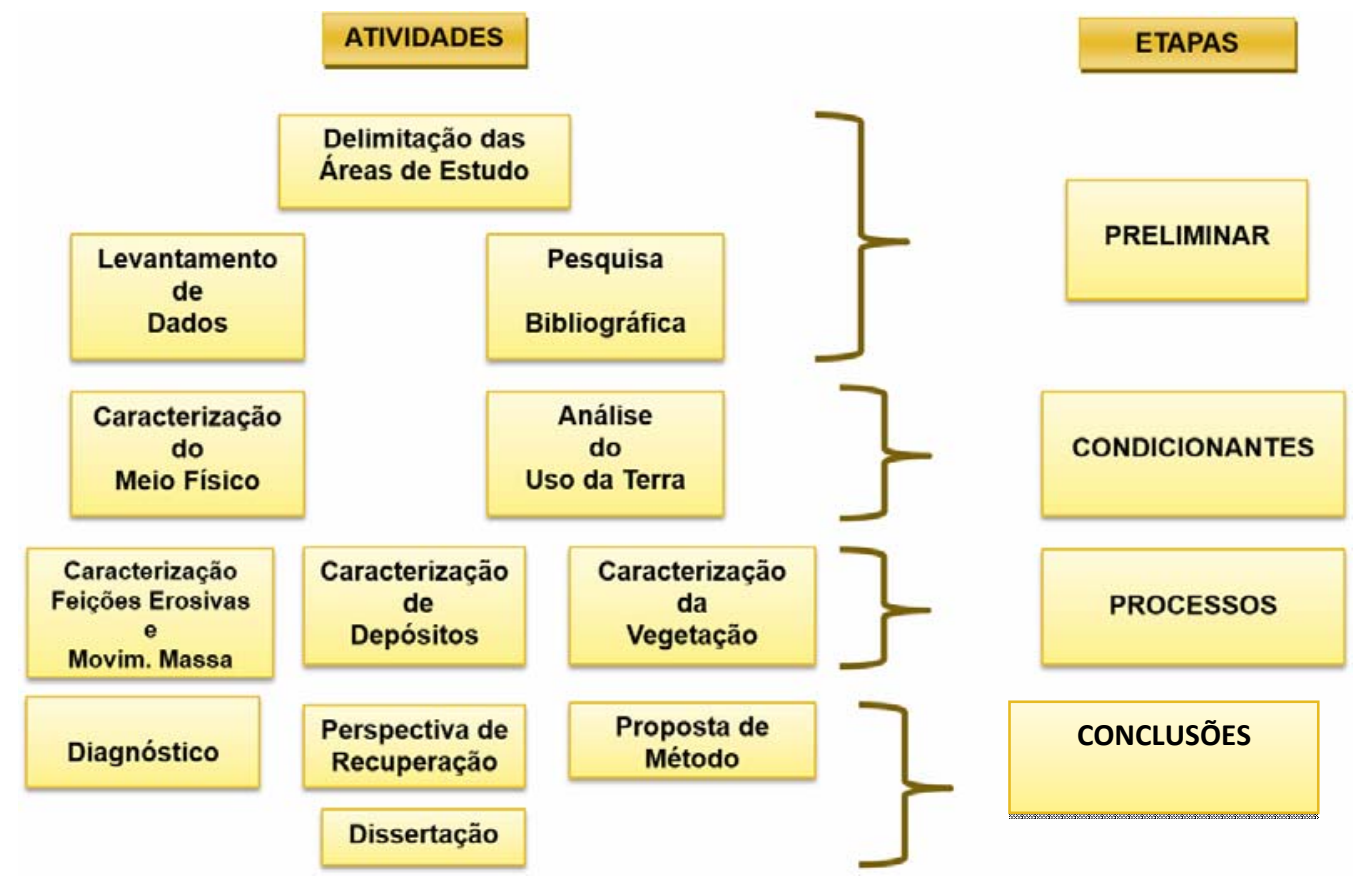

Figura 3: Fluxograma das etapas da pesquisa

Foi realizada análise do uso da terra por meio da elaboração de mapas de ocupação do solo de diversas

datas até a atual, com base em interpretação de fotos 
aéreas e imagens de satélites disponíveis, conforme apresenta o quadro 1.

Os materiais utilizados estão apresentados no quadro 2, de acordo com as etapas de desenvolvimento da pesquisa.

Quadro 1: Fotos aéreas interpretadas para a elaboração dos mapas de uso da terra

\begin{tabular}{ccc}
\hline $\begin{array}{c}\text { LEVANTAMENTO } \\
\text { AEROFOTOGRAMÉTRICO }\end{array}$ & DATA & ESCALA \\
\hline IAC & 1962 & $1: 25.000$ \\
IBC & & \\
GERCA & 1970 & $1: 20.000$ \\
EMPLASA & & $1: 10.000$ \\
ELETROPAULO & 1986 & \\
SABESP & & $1: 25.000$ \\
P.M.G. & 1994 & $1: 1.000$ \\
P.M.G. & 2010 & \\
\hline
\end{tabular}

Quadro 2: Materiais utilizados de acordo com as etapas da pesquisa

\begin{tabular}{|c|c|c|}
\hline \multicolumn{3}{|c|}{ ETAPAS } \\
\hline $\begin{array}{l}\text { PRELIMINAR } \\
\text { Bibliografia } \\
\text { Teses } \\
\text { Artigos } \\
\text { Relatórios } \\
\text { Técnicos } \\
\text { DADOS } \\
\text { DISPONIVEIS } \\
\text { Carta Topográfica } \\
\text { Fotos Aéreas } \\
\text { Imagens } \\
\text { satélite } \\
\text { A montagem de } \\
\text { base de dados } \\
\text { espaciais } \\
\text { realizada em } \\
\text { ambiente SIG }\end{array}$ & $\begin{array}{l}\text { CONDICIONANTES } \\
\text { Reconhecimento de } \\
\text { Campo } \\
\text { Fotos Aéreas } \\
\text { Imagens de satélite } \\
\text { Estereoscópio } \\
\text { Digitalização dos } \\
\text { mapas de ocupação } \\
\text { em ArcGis. }\end{array}$ & $\begin{array}{l}\text { PROCESSOS } \\
\text { Fotos Aéreas } \\
\text { Imagens de } \\
\text { satélite } \\
\text { Campo } \\
\text { GPS } \\
\text { Trena } \\
\text { Nivel de bolha } \\
\text { Maquina } \\
\text { fotográfica } \\
\text { Carta de cores } \\
\text { de solo Munsell } \\
\text { Trado }\end{array}$ \\
\hline
\end{tabular}

\section{Fundamentos}

Na escala de tempo geológico, a presença do homem na Terra, como gênero, inicia-se no período Quaternário. Em razão disso, Pavlov (1922) apud Oliveira (1994) propôs a substituição do tema Quaternário para Antropógeno, mantendo porém a época Pleistoceno.

Considerações e estudos sobre os efeitos da ação do homem na Terra não são recentes, Vernadsky em 1945 destaca em seu artigo The Biosphere and the Noosphere:

"Following the concept of geologic role of man, Geologist A. P. Pavlov (1854-1929), the last years of his life used to speak of anthropogenic era in which we live. While he did not take into account the possibility of the destruction of the spiritual and material values which today bears witness to the barbaric invasion of the Germans and their allies, just over ten years after his death, he stressed that the timely man, with our full consent, is becoming an increasingly powerful geological force.
This geological strength was formed almost imperceptibly over a long period of time. The change of position of man on our planet (material to their position first) coinciding with her. In the twentieth century, the man for the first time in Earth's history, knew and embraced the entire biosphere, completed the geographical map of planet Earth and colonized the whole surface. Mankind has become a single set of earth life", Vernadsky (1945).

Para Ter-Stepanian (1988), o Holoceno seria a transição entre o Quaternário ou época Pleistoceno e o período Quinário ou a época do Tecnógeno, tendo como marco inicial a revolução agrícola (10.000 AP) em razão das grandes mudanças na natureza com a passagem do homem de coletor e caçador para produtor de alimentos.

Ter-Stepanian (1988) apud Oliveira et al. (2005) explica que o começo da transição foi caracterizado pela completa configuração quaternária da paisagem, há cerca de 10.000 anos, enquanto seu fim será marcado, no futuro, pela completa configuração quinária. Em resumo, afirma: “O Holoceno é o começo do Tecnógeno”, indicando que o final do Holoceno corresponderá ao momento em que as condições ambientais modificadas (tecnogênicas) serão preponderantes na Terra.

Crutzen \& Stoermer (2000) propuseram o Antropoceno como nova época a partir da Revolução Industrial. Em sua proposta estes autores fazem uma retrospectiva histórica do tema, considerando que o termo Holoceno, para denominar a época geológica pós-glacial dos últimos 10 a 12 mil anos, foi proposto pela primeira vez por Sir Charles Lyell, em 1833, e adotado pelo Congresso Internacional de Geologia em Bolonha, em 1885.

Crutzen \& Stoermer (2000) relatam também que: The man started to now highlight in 1864 when G. P. Marsh published a book with the title "Man and Nature", recently reissued as "The Earth as Modified by Human Action." Stoppani in 1873 classifying the activities of mankind as $a$ "new telluric force which in power and universality may be compared to larger forces of the earth "said Clark. Stoppani antropozóica was talked of.

... continue growing human actions on the earth and the atmosphere, including global scales, it seems more than appropriate to emphasize the central role of mankind in geology and ecology by proposing to use the term 'Anthropocene' for the current geological epoch.

The impacts of current human activities continue for long periods. According to a study by Berger and Loutre, because of anthropogenic C02 emissions, the climate can differ significantly from natural behavior in the next 50,000 years. 
Antropoceno - Tecnógeno

Para atribuir uma data mais específica para o início do Antropoceno os autores referidos propõem a última parte do século 18, apesar de estarem cientes de que outras propostas podem ser feitas (alguns podem até querer incluir todo o Holoceno). Entretanto, escolheram esta data porque, durante os últimos dois séculos, os efeitos globais das atividades humanas tornaram-se claramente perceptíveis.

This is the period during which recovered data samples shown glacial ice early growth in atmospheric concentrations of various greenhouse gases, especially $\mathrm{CO} 2$ and $\mathrm{CH} 4$.

Such a starting date also coincides with James Watt's invention of the steam engine in 1784 (Crutzen \& Stoermer 2000).

O quadro 3 foi elaborado no intuito de comparar o tempo geológico convencional com as propostas de Pavlov (1922), Ter-Stepanian (1988) e Crutzen \& Stoermer (2000).

Quadro 3: Quadro comparativo do tempo geológico convencional e as propostas de Pavlov (1922), Ter-Stepanian (1988) e Crutzen; Stoermer (2000).

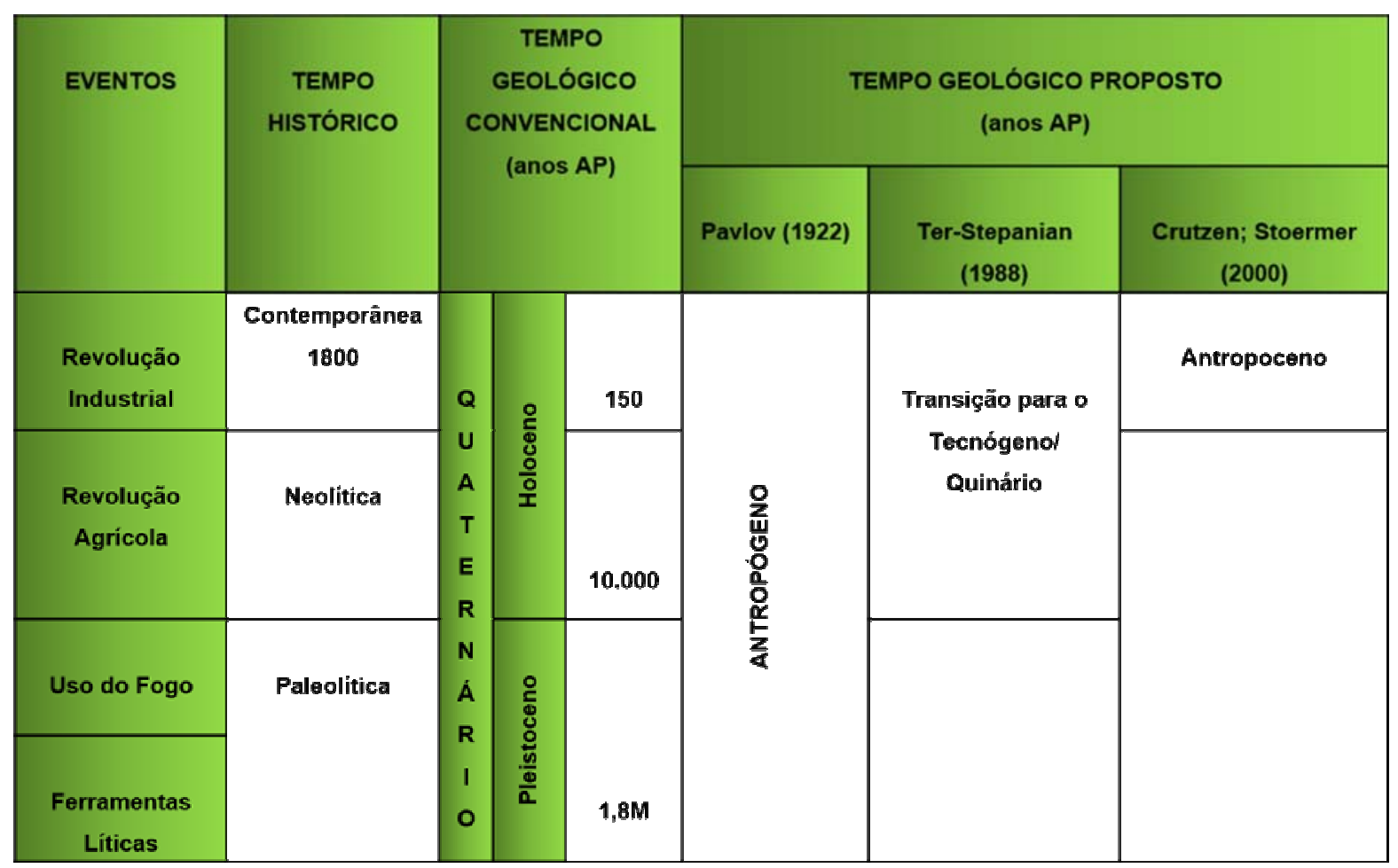

Como testemunhos do Tecnógeno ou Antropoceno, comparáveis às formações geológicas foram reconhecidos os depósitos tecnogênicos (Chemekov 1983).

A principal característica dos depósitos tecnogênicos é o fato de surgirem, exclusivamente, pela ação direta ou indireta humana. Esta afirmação está presente nos escritos de Chemekov (1983) conforme mencionado por Peloggia (1996).

No que diz respeito à classificação (ordenação e hierarquização dos tipos de depósitos), Oliveira et al. (2005) ressaltam que é ponto fundamental ter claro, na caracterização de um depósito tecnogênico, enquanto registro geológico gerado pela atividade humana, o conceito de depósito correlativo, ou seja, que corresponde a determinada ação específica; isto é, não existiria, ao menos naquela forma e expressão, sem uma ação que pode ser assim determinada e especificada e, uma vez feito isto, a caracterização do depósito decorre dela, mesmo que faltem atributos litológicos diferenciadores.

Peloggia (1999 apud Oliveira et al. 2005) propõe quanto à classificação:
1) depósitos de primeira ordem ou geração, a partir da sistemática geral proposta por Oliveira (1990), que diferencia depósitos construídos (resultantes da ação humana direta; por exemplo, aterros); induzidos (resultantes de processos naturais modificados; por exemplo, assoreamento produzido por erosão antrópica) e mo19dificados (depósitos naturais preexistentes, mas alterados; por exemplo, solo contaminado); e

2) de segunda ordem, depósitos remobilizados (por exemplo, depósitos de fundos de vale formados por escorregamentos de aterros) e retrabalhados (propostos por Nolasco 2000); por exemplo, aterros ravinados).

Nolasco (2002) apresenta outra classificação para os depósitos tecnogênicos:

1) diretos: depósitos construídos (realizados pelo homem, como, por exemplo, aterros); induzidos (realizados pela ação humana com o uso planejado de outro agente; por exemplo, depósitos resultantes de escorregamentos provocados em minerações); e 
Antropoceno - Tecnógeno

2) indiretos: resultantes da soma de ações do agente homem, sem intencionalidade, com as de outros agentes (por exemplo, leques de escorregamento de encosta em áreas urbanas por acúmulo de lixo e peso de construções).
O quadro 4 apresenta uma síntese das diversas classificações que têm sido usadas na literatura brasileira.

Quadro 4: Classificações de depósitos tecnogênicos utilizados no Brasil.

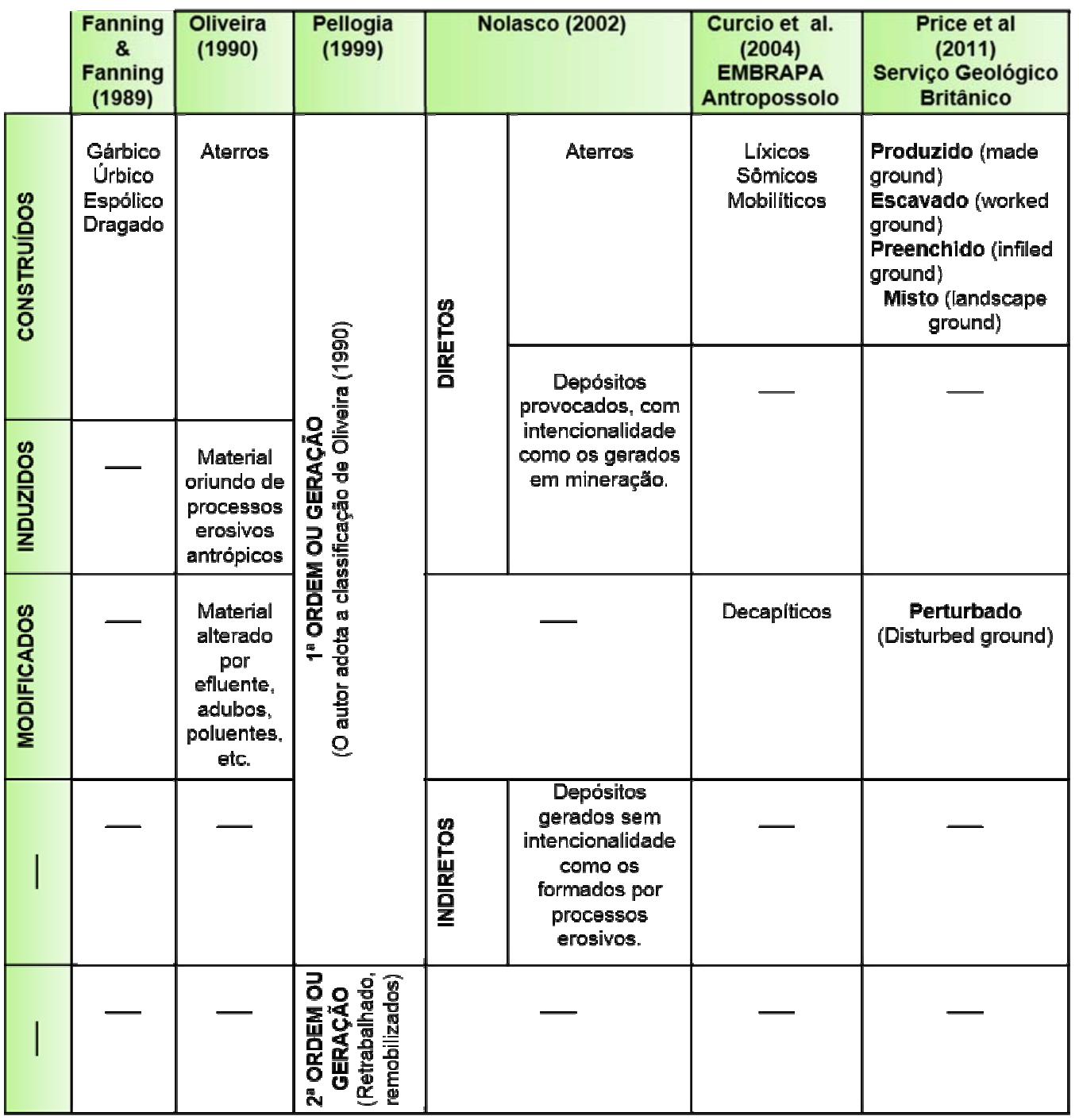

Ao se estudar a questão das formações de depósitos tecnogênicos, pode-se considerar a ação humana na natureza em três níveis de abordagem, com consequências geológico-geomorfológicas conforme estabelecido por Peloggia (1996), tendo como referência Ab’Saber (1969).

1) $\mathrm{Na}$ modificação do relevo e alterações fisiográficas (por exemplo, padrões de canais fluviais, terraplanagem, surgimento de voçorocas e áreas erodidas, áreas mineradas etc.) Ter-Stepanian (1988) refere-se a tais efeitos como "novos tipos de relevo tecnogênico”, Fanning \& Fanning (1989) chamam de "superfícies descapadas" (scalped land surfaces) as paisagens resultantes da ação do homem como agente geomorfológico. (...)

2) Em alterações na fisiologia das paisagens (os processos morfoclimáticos e pedogênicos atuais, em sua plena atuação, conforme a conceituação de Ab’Saber (1968, 1969a): criação, indução, intensificação ou modificação do comportamento de processos da dinâmica externa (incremento da erosão e da carga sedimentar correlativa, escorregamentos em geral, infiltração, fluxos subterrâneos etc.), de porte comparável aos resultantes de variações climáticas ou dos efeitos dos movimentos tectônicos; nas áreas urbanas, resultando em uma outra organização da fisiologia da paisagem criada pelo construtivismo. Conforme já observava o autor citado, "evidentemente, variações sutis de fisiologia podem ser determinadas por ações antrópicas predatórias, as quais na maior parte dos casos são irreversíveis em relação ao metabolismo primário do meio natural”. 
Antropoceno - Tecnógeno

3) Na criação de depósitos superficiais correlativos comparáveis aos quaternários (os depósitos tecnogênicos ou, como pode ser encontrado na literatura norte-americana, solos influenciados pelo homem - man-influenced soils: aterros, depósitos de "bota-fora", coberturas remobilizadas, depósitos de assoreamento), os quais vão se constituir em marcos estratigráficos. Este caráter é indiretamente ressaltado por Fanning \& Fanning (1989): “Do ponto de vista de gênese dos solos, a destruição e formação de solos pelo homem, pela grande manipulação física dos materiais terrosos, são eventos catastróficos que criam novos pontos de partida para a formação dos solos” (Pellogia 1996).

\section{Meio físico e o uso da terra}

Conforme Andrade (1999), o município de Guarulhos tem um clima do tipo úmido, dominado por massas de ar de origem tropical e polar, que são influenciadas por correntes atmosféricas polares marítimas, pela frente polar atlântica e equatorial marítima por influência de alísios de sudeste.

Ainda segundo o autor, em termos de domínio climático, Guarulhos tem como característica predominante o Mesotérmico Brando Úmido, com um ou dois meses secos. A temperatura média anual está entre $18^{\circ} \mathrm{C}$ e $19^{\circ} \mathrm{C}$, sendo a média do mês mais quente inferior a $22^{\circ} \mathrm{C}$ e do mês mais frio inferior a $15^{\circ} \mathrm{C}$. A pluviosidade média anual é da ordem de $1.500 \mathrm{~mm}$.

A área situa-se na transição entre as colinas e morrotes ao sul do município e os morros e montanhas ao norte no domínio geomorfológico do Planalto Atlântico, conforme a figura 4.

A microbacia estudada está na zona de transição entre os compartimentos do relevo norte e sul, do território de Guarulhos, contendo parte de uma colina grande a sul e parte de morrote e morro a norte (Oliveira et al. 2009).

Litologicamente, situa-se em terrenos cristalinos, metassedimentares, predominando os filitos. Os solos derivados deste substrato são latossolos pouco espessos e cambissolos amarelos, argilosos.

O reconhecimento de campo na área estudada confirmou a presença destes tipos pedológicos, o latossolo amarelo pouco profundo e cambissolo de textura argilosa.

A área de estudo situa-se no limite da ocupação urbana de Guarulhos, conforme figura 5. A microbacia localiza-se na periferia da área urbana em transição com área de cobertura vegetal.

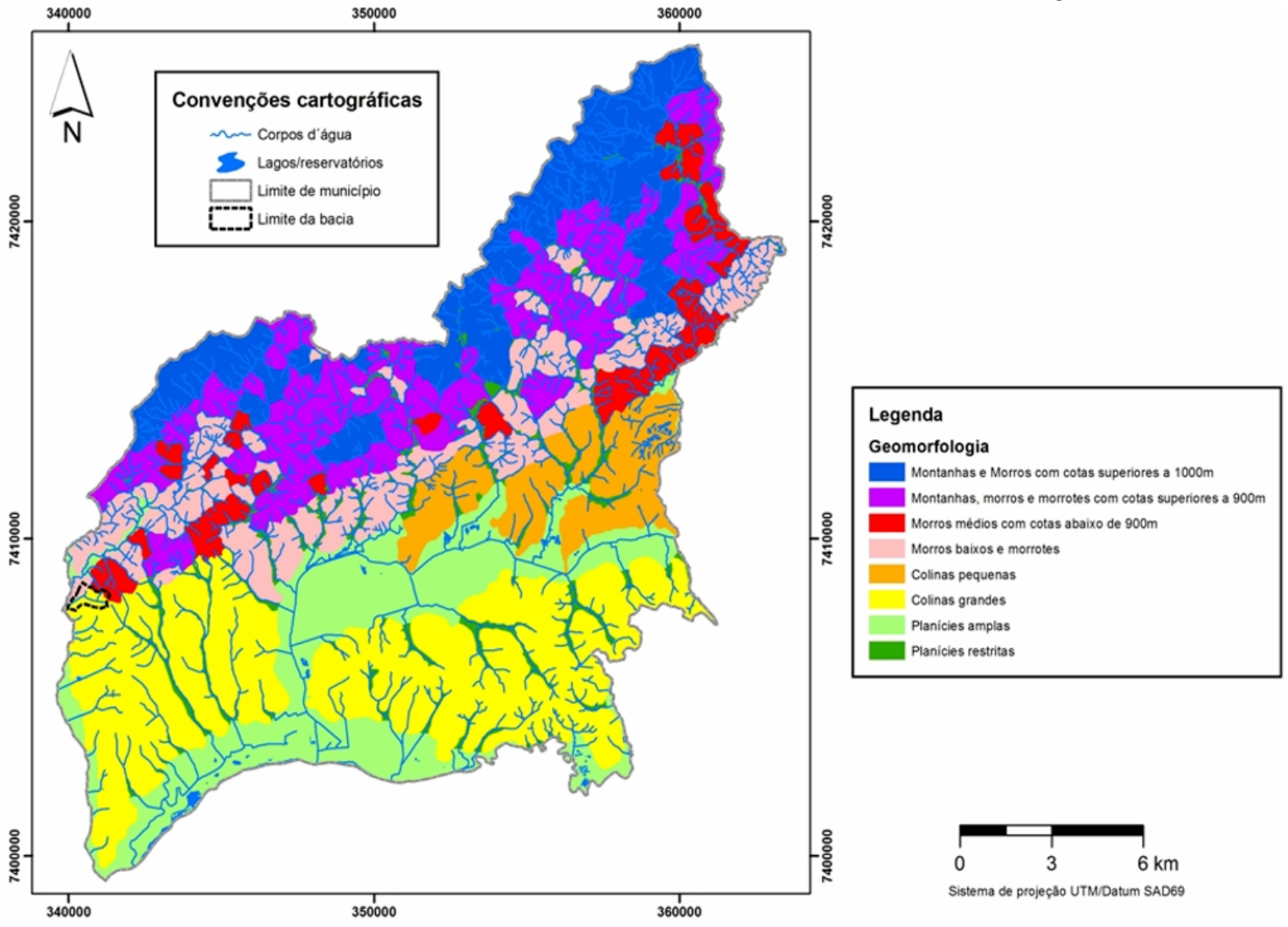

Figura 4: Mapa geomorfológico de Guarulhos Fonte: Oliveira et al. (2009) 


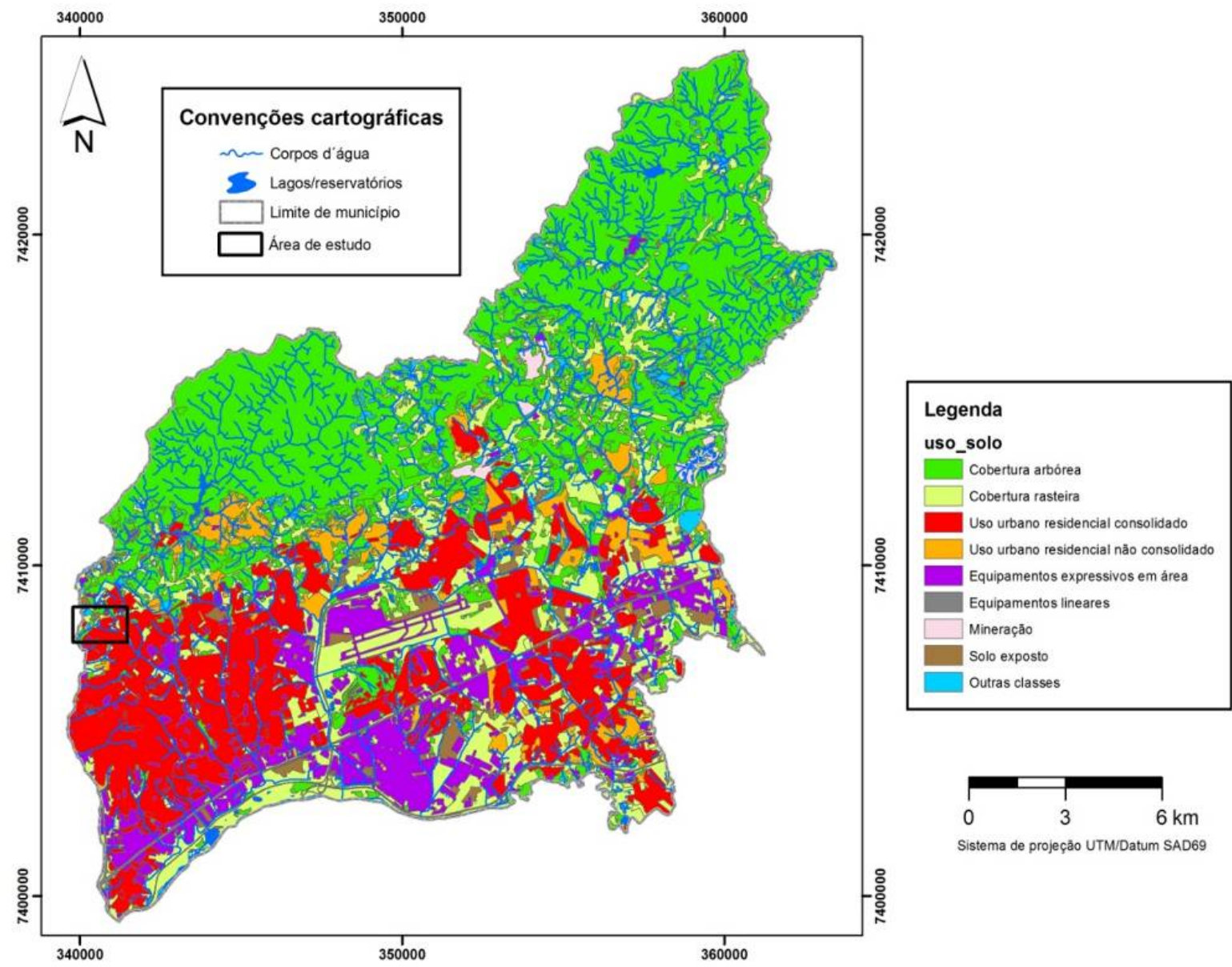

Figura 5: Mapa de uso da terra de Guarulhos Fonte: Oliveira et al. (2009)

O aspecto mais importante do uso do solo do município é o grande contraste existente entre a ocupação urbana, com elevada densidade a sul, e a cobertura vegetal a norte onde se observa crescente avanço das áreas urbanas não consolidadas, numa área que presta importantes serviços ecossistêmicos para a população. A área de estudo fica exatamente entre estes dois setores.

\section{A transformação geotecnogênica da área de estudo}

Conforme a abordagem geotecnogênica é fundamental analisar o uso da terra tendo em vista que sua transformação se dá pela ação do homem como agente geológico.

A figura 6 mostra a evolução do uso da Terra na microbacia do Parque Continental II através dos mapas foto interpretados dos anos de 1962, 1970, 1986, 1994 e 2010.

Em 1962 não havia uso urbano na microbacia, e a mata ocupava $64,4 \%$ do total da área.

No ano de 1970, houve um aumento da vegetação arbustiva, herbácea e agrícola, e diminuição da mata, porém sem sinal de urbanização.

Dezesseis anos depois, em 1986, observa-se intensa transformação, representada pela consolidação do loteamento do Jardim Palmira, diminuição do uso agrícola e aparecimento de solo exposto no fundo do vale, correspondente a assoreamento.

Em 1994, há a predominância de solo exposto, área urbana consolidada, em consolidação e aumento da área da microbacia, devido ao corte realizado na área degradada, revelando a transformação geotecnogênica.

No último mapa, de 2010, observa-se o predomínio da área urbana na microbacia.

Correspondentes a cada um dos mapas foram elaborados gráficos com o percentual da distribuição de cada classe de uso da terra. Estes gráficos estão apresentados na figura 7 .

Em termos de intensidade da intervenção antrópica na área, pode-se considerar que os processos geotecnogênicos se diferenciam em antes e depois da implantação dos loteamentos.

\subsection{Processos geotecnogênicos da área de estudo}

Os processos geológicos identificados na microbacia estudada são, por definição, decorrentes da ação antrópica, ou seja, correspondem à intervenção tecnológica de terraplenagem, tendo sido identificados principalmente como erosão, movimento de massa e assoreamento. A localização de tais processos encontra-se na figura 8. 


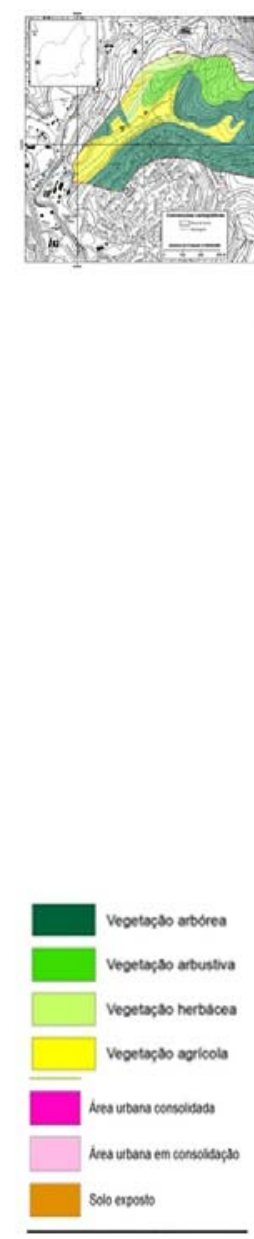

\section{2}

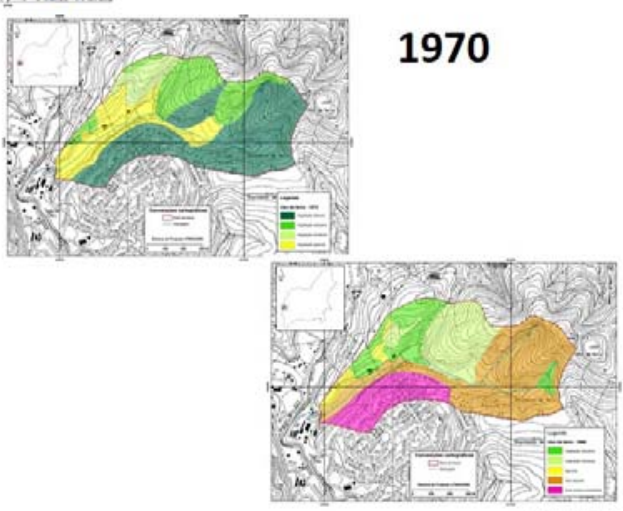

Figura 6: Mapas do uso da terra foto interpretadas da microbacia dos anos de 1962, 1970, 1986, 1994 e 2010

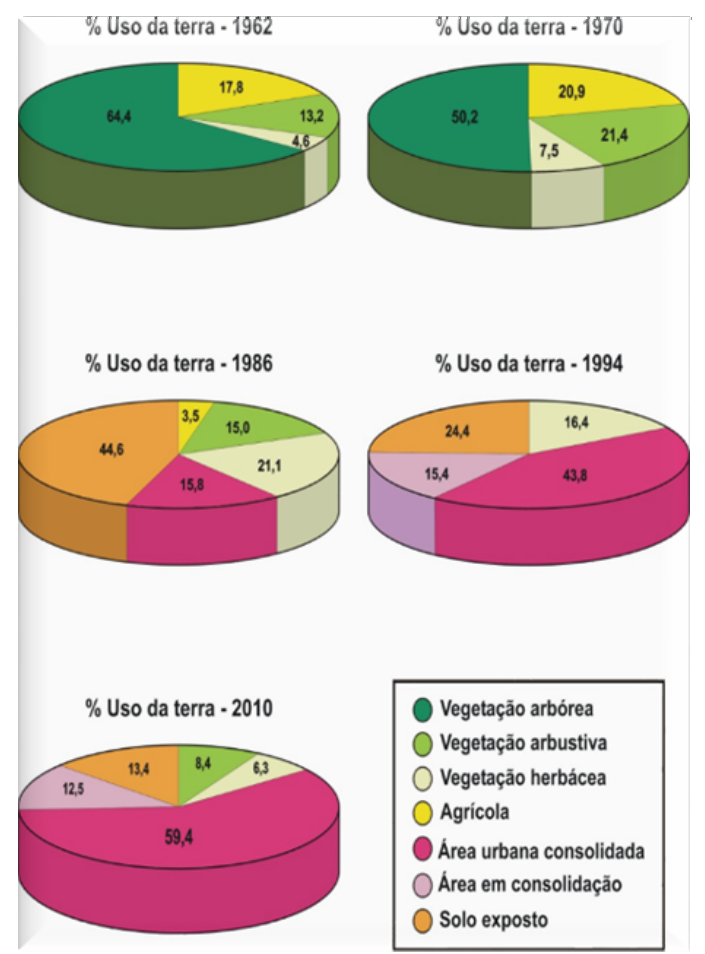

Figura 7: Gráficos da evolução do uso da terra dos anos de 1962 a 2010

\subsection{Ocorrências do processo tecnológico gerador da área degradada}

O processo tecnológico de terraplenagem gerador da área degradada na microbacia foi realizado no ano de 1993, ocasionando intensos impactos ambientais que motivaram a abertura de processo, embargando a área em 1994.

\subsubsection{Histórico}

- O processo tecnológico de terraplenagem: ano 1993

- Embargo da prefeitura: ano 1994

- Área total de terraplenagem: $126.000 \mathrm{~m}^{2}$

- Volume estimado de material mobilizado: $200.000 \mathrm{~m}^{3}$.

A terraplenagem apresenta-se geotecnicamente imprópria por:

1) Mobilizar um grande volume de material e dispor em aterros não compactados;

2) Deixar exposta à erosão grandes superfícies de corte e aterro de material altamente erodível.

3) Aterrar um fundo de vale onde ocorrem argilas sujeitas a recalques, bem como alterar uma área onde ocorria infiltração de águas pluviais. 


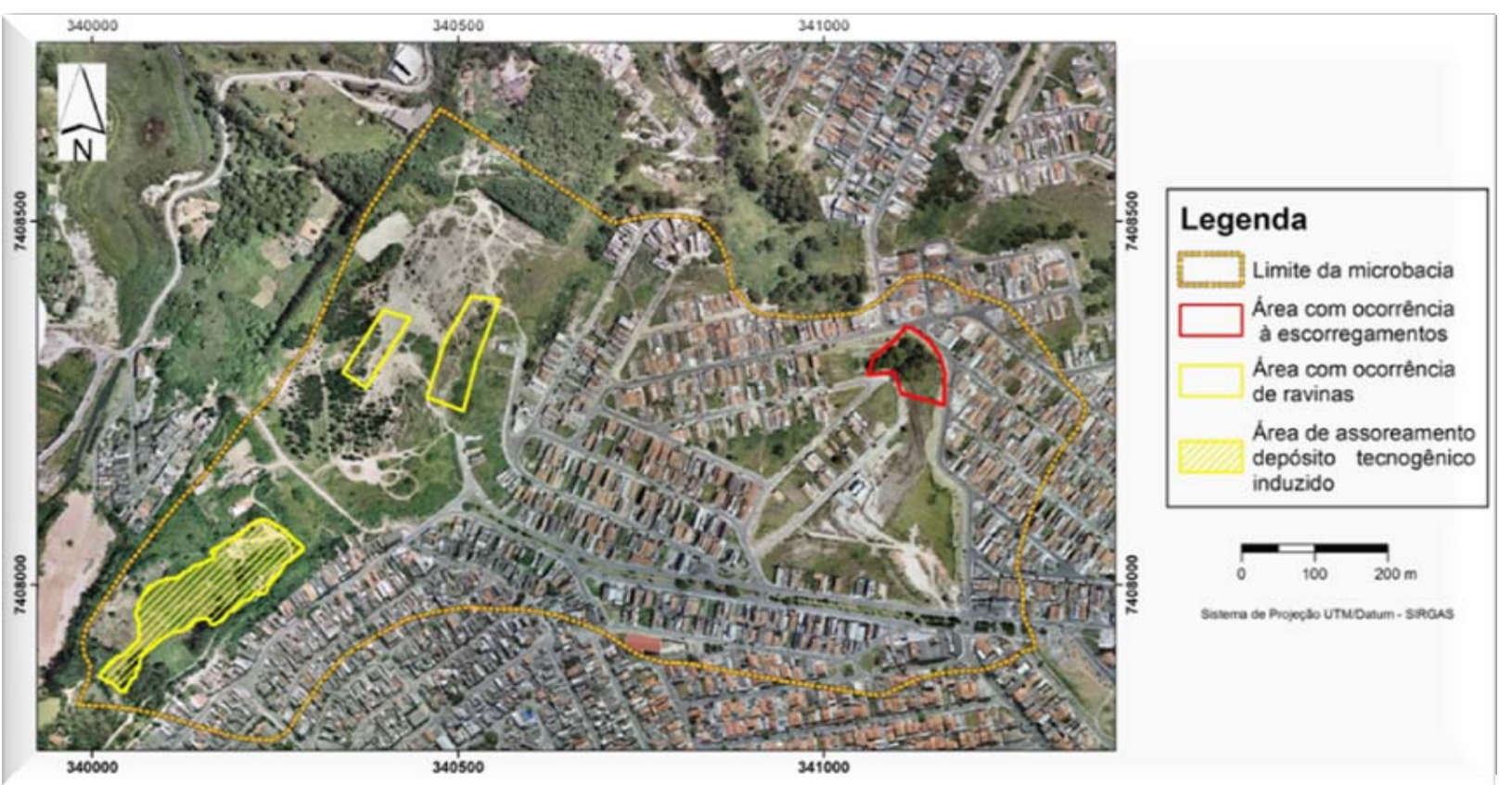

Figura 8: Mapa das feições dos principais processos geotecnogênicos atualmente presentes na microbacia. Fonte: (Imagem de satélite P.M.G. 2009)

\subsubsection{Cobertura vegetal da área degradada}

Foram realizadas duas avaliações da cobertura vegetal da área degradada: uma avaliação no corte e no aterro, e uma avaliação da vegetação adjacente ao talude de corte, presumindo-se que seja representante da vegetação original suprimida na terraplenagem.

As informações coletadas permitiram caracterizar a cobertura vegetal atual como uma formação pioneira, em estágio inicial de regeneração. Esta condição é resultante do abandono da área após terraplenagem executada (figura 9).

Como conclusões principais das observações realizadas em campo, destacam-se atualmente, quanto à vegetação:

a) A cobertura vegetal privilegia as áreas de aterro, do lado direito (oeste) o Pinnus, e do esquerdo (leste) as gramíneas que avançam para o centro da gleba;

b) Na área central da gleba há de forma geral pouca vegetação, pois predomina a área de corte em rocha alterada.

É possível verificar uma relação da vegetação com os processos erosivos (figuras 10 e 11).

- As erosões são pronunciadas nas áreas de aterro, sendo mais evidentes na área de concentração de Pinnus do que na outra área, onde se encontram cobertas por gramíneas;

- Na área central da gleba as erosões não são pronunciadas, devido à resistência da rocha em corte.

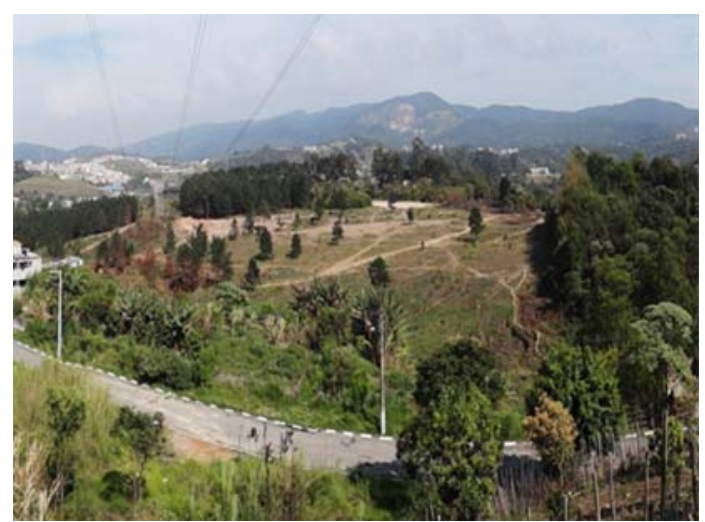

Figura 9: Imagem da área degradada com pouca vegetação em sua parte central, a área de corte em rocha alterada. Foto de A. A. Oliveira, 2013

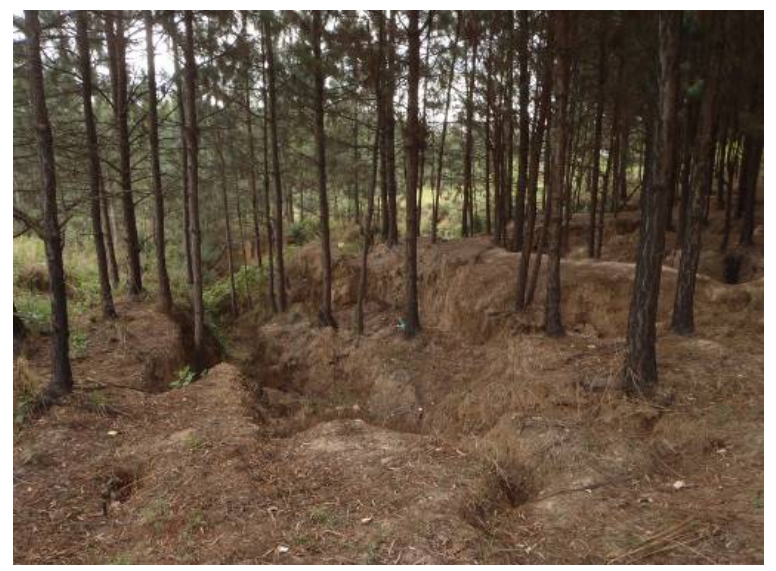

Figura 10: Erosões na área de concentração de Pinnus. Foto de A. A. Oliveira, 2013 
Antropoceno - Tecnógeno

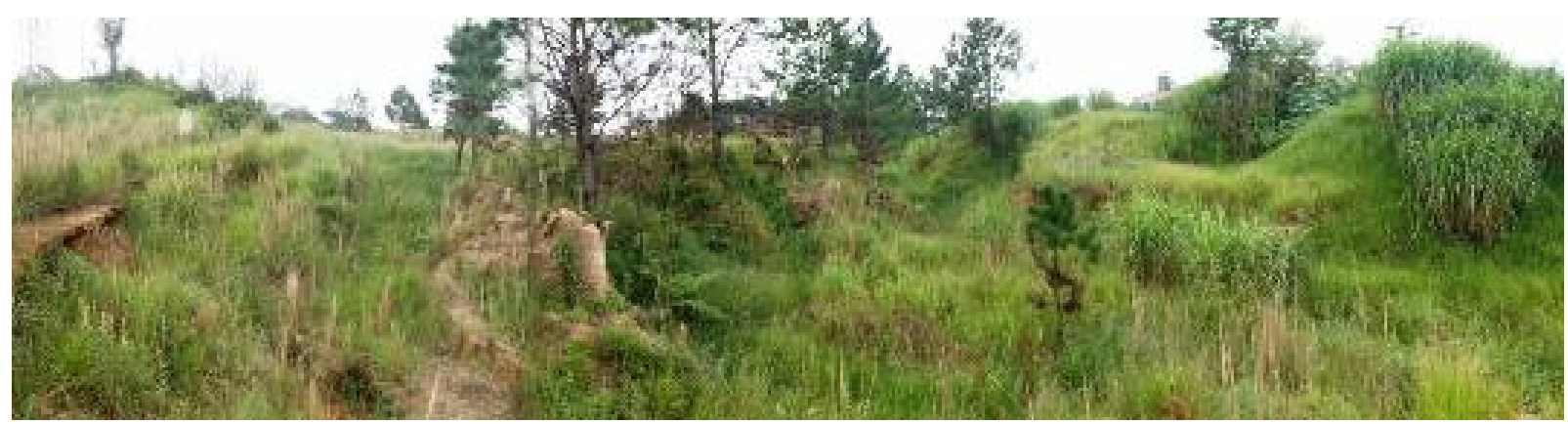

Figura 11: As erosões na área de gramíneas são pouco visíveis. Foto de A. A. Oliveira, 2013

\subsubsection{Dinâmica dos processos geotecnogênicos da área degradada}

Faltam registros e relatos da forma como se deu a terraplenagem, sendo possível reconstituir o procedimento apenas por observações de campo e da foto da figura 12, que pode ser considerada como o primeiro registro da área após o terrapleno realizado. A partir desta foto foi possível criar um mapa de setores da área degradada: área de talude, setor de corte, de aterro, e uma pequena porção que não sofreu a intervenção (figura 12).

Uma nova paisagem tecnogênica foi criada na área degradada da microbacia a partir da terraplenagem que resultou em significativos volumes de terra mobilizados por corte e aterro.

Um mapa das unidades geotecnogênicas da nova paisagem foi elaborado e pode ser visto na figura 13; a descrição dessas unidades está no quadro 5.

\subsubsection{Processos Geotecnogênicos da área degradada}

$\mathrm{Na}$ área degradada, os aterros não foram compactados e apresentam composição predominantemente siltosa. Os processos erosivos manifestaram-se logo em seguida à intervenção, como mostra a figura 12, e revelam a baixa compacidade dos depósitos tecnogênicos construídos, os aterros.

No setor de corte verifica-se a ocorrência de erosão laminar e em pequenos sulcos, gerados pelo processo de desplacamento do filito, provavelmente favorecido pelo fenômeno de expansividade de minerais presentes (figura 14).

As mais expressivas erosões estão representadas por duas grandes ravinas (R-1 e R-2), conforme mostra a figura 12 e o quadro 6 .

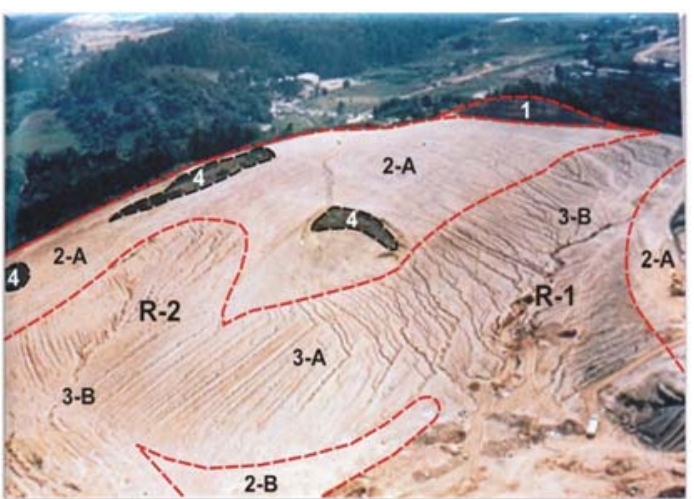

Figura 12: Mapa das unidades geotecnogênicas da área degradada. Setor 1 - talude de corte; setor 2 - área de corte; setor 3 - área de aterro; e setor 4 - área sem intervenção. R-1 - ravina 1 e R-2 - ravina 2. Foto de M. R. M. Andrade, 1993

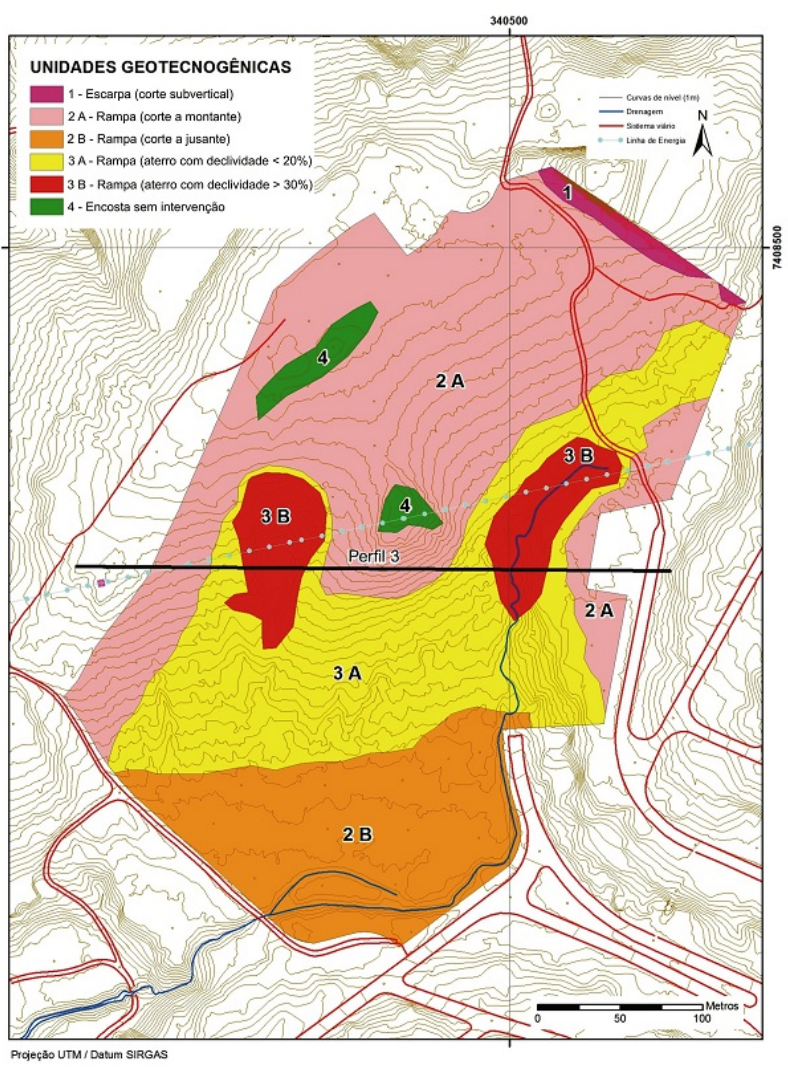

Figura 13: Mapa das unidades geotecnogênicas da área degradada 
Quadro 5: Unidades geotecnogênicas da área degradada

\begin{tabular}{|c|c|c|c|c|c|c|c|}
\hline \multirow{2}{*}{ 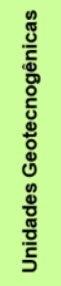 } & \multicolumn{3}{|c|}{ Compartimentos } & \multirow[b]{2}{*}{ 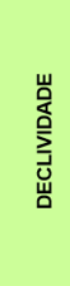 } & \multirow[b]{2}{*}{ 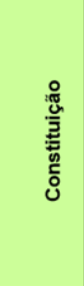 } & \multirow[b]{2}{*}{$\begin{array}{c}\text { Cobertura } \\
\text { (atual) }\end{array}$} & \multirow[b]{2}{*}{$\begin{array}{c}\text { Processos } \\
\text { Geotecnogênicos } \\
\text { (atuais) }\end{array}$} \\
\hline & 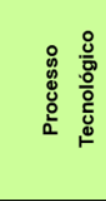 & 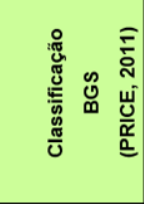 & 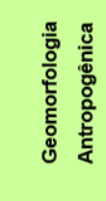 & & & & \\
\hline $\begin{array}{c}\text { Setor } \\
1\end{array}$ & 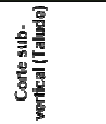 & 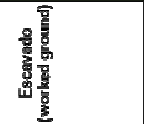 & 营 & $>30 \%$ & 蛋高 & $\begin{array}{c}\text { Briotthas } \\
\text { em } \\
\text { rocha exposta }\end{array}$ & Erosto laminar \\
\hline $\begin{array}{c}\text { Setor } \\
\text { 2-A }\end{array}$ & 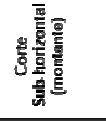 & 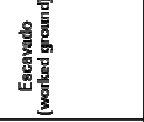 & 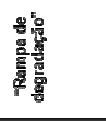 & $<12 \%$ & 量哥 & $\begin{array}{c}\text { Com algumas Gramineas e Phonus } \\
\text { [esparsos) }\end{array}$ & $\begin{array}{l}\text { Erosho laminar } \\
\text { Erosito em sulcos }\end{array}$ \\
\hline $\begin{array}{c}\text { Setor } \\
\text { 3-A }\end{array}$ & $\frac{9}{8}$ & 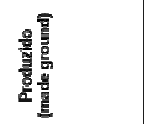 & 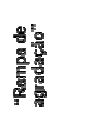 & $420 \%$ & 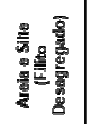 & 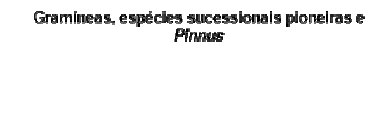 & $\begin{array}{c}\text { Erosăo om sulcos } \\
\text { Erosio ravinar }\end{array}$ \\
\hline $\begin{array}{c}\text { Setor } \\
\text { 3-B }\end{array}$ & 量 & 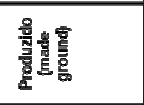 & 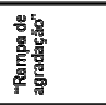 & $>30 \%$ & 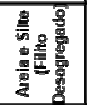 & $\begin{array}{l}\text { Gramineas e } \\
\text { Pinners }\end{array}$ & Erosato ravinar \\
\hline $\begin{array}{c}\text { Setor } \\
4\end{array}$ & 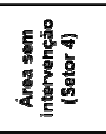 & 1 & 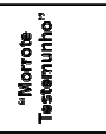 & $<10 \%$ & 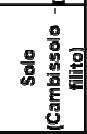 & Gramineas, especles sucesslonals ploneiras & Erossăo Laminar \\
\hline
\end{tabular}

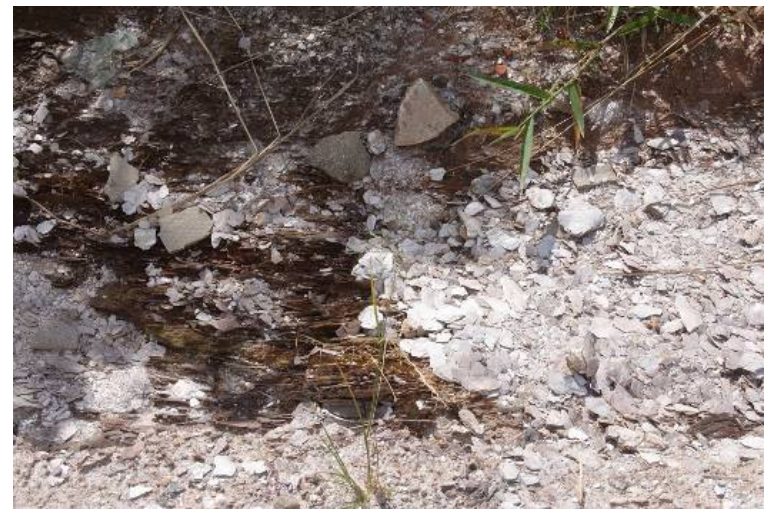

Figura 14: Processo de desplacamento do filito, formando pastilhas. Foto de A. A. Oliveira, 2013

Quadro 6: Principais ravinas da área degradada

\begin{tabular}{|c|c|c|c|c|}
\hline Erosão & 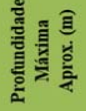 & 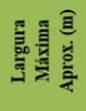 & 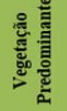 & Observação \\
\hline $\begin{array}{c}\text { Ravina } \\
\text { (R-1) }\end{array}$ & 4,0 & 15,0 & 害 & $\begin{array}{c}\text { A ravina corta } \\
\text { parxialmeate o } \\
\text { aterro. }\end{array}$ \\
\hline $\begin{array}{c}\text { Ravina } \\
\text { (R-2) }\end{array}$ & $\mathbf{5 , 0}$ & 6,0 & 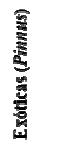 & $\begin{array}{l}\text { A ravina corta todo } \\
\text { o aterio e } \\
\text { aprofunda-se na } \\
\text { rocha alterada. }\end{array}$ \\
\hline
\end{tabular}

\subsubsection{Depósitos Tecnogênicos da área degradada}

Os depósitos tecnogênicos da área degradada ocorrem nas áreas de aterro e na área de corte a jusante. Esta última ocorrência constitui depósito pouco espesso em rampa de baixa declividade, frequentemente alagada no período de chuvas, com gramíneas e a presença de lírio do brejo (Hedychium coronarium), indicando área encharcada compatível com a deposição de sedimentos na área de corte, na formação contínua em curso, com aporte de sedimentos das ravinas instaladas nos aterros, constituindo portanto um depósito induzido de 2. ${ }^{a}$ geração, remobilizado, segundo Peloggia (1999).

Os depósitos mais expressivos e que testemunham os processos tecnológicos são os depósitos correspondentes aos aterros, descritos nos Pontos A e $\mathrm{B}$, onde estão as ravinas 1 e 2, localizadas na área degradada, conforme figura 15 .

No Ponto A, foram realizados quatro perfis em talude e um por sondagem a trado, conforme apresenta a figura 16, onde se observa que os perfis foram realizados de forma escalonada aproveitando o entalhe da ravina, em níveis $\mathrm{N}-1$ a N-4. 


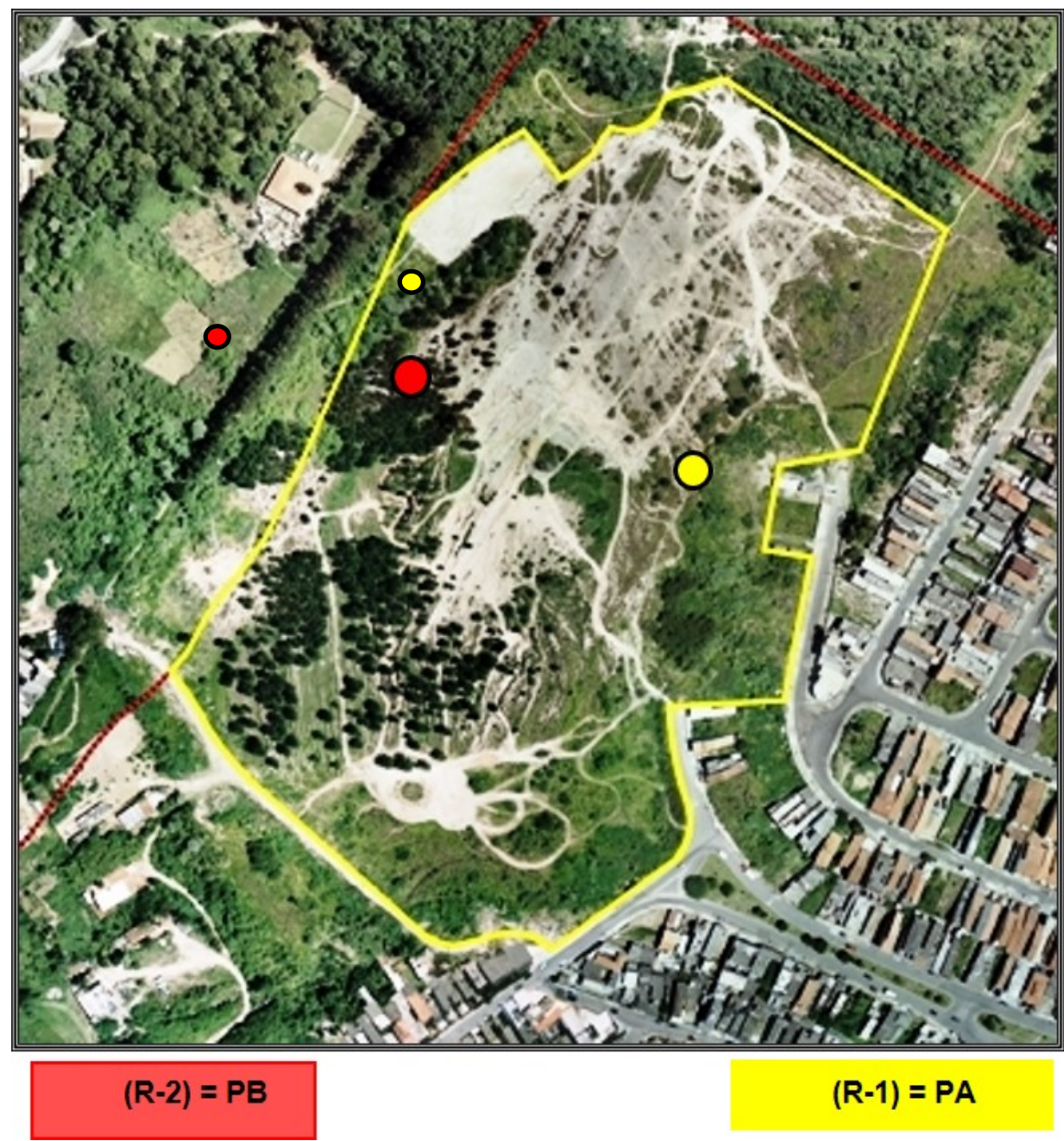

Figura 15: Pontos onde foram realizados os perfis de depósitos tecnogênicos. Fonte: (foto aérea P.M.G. 2009)

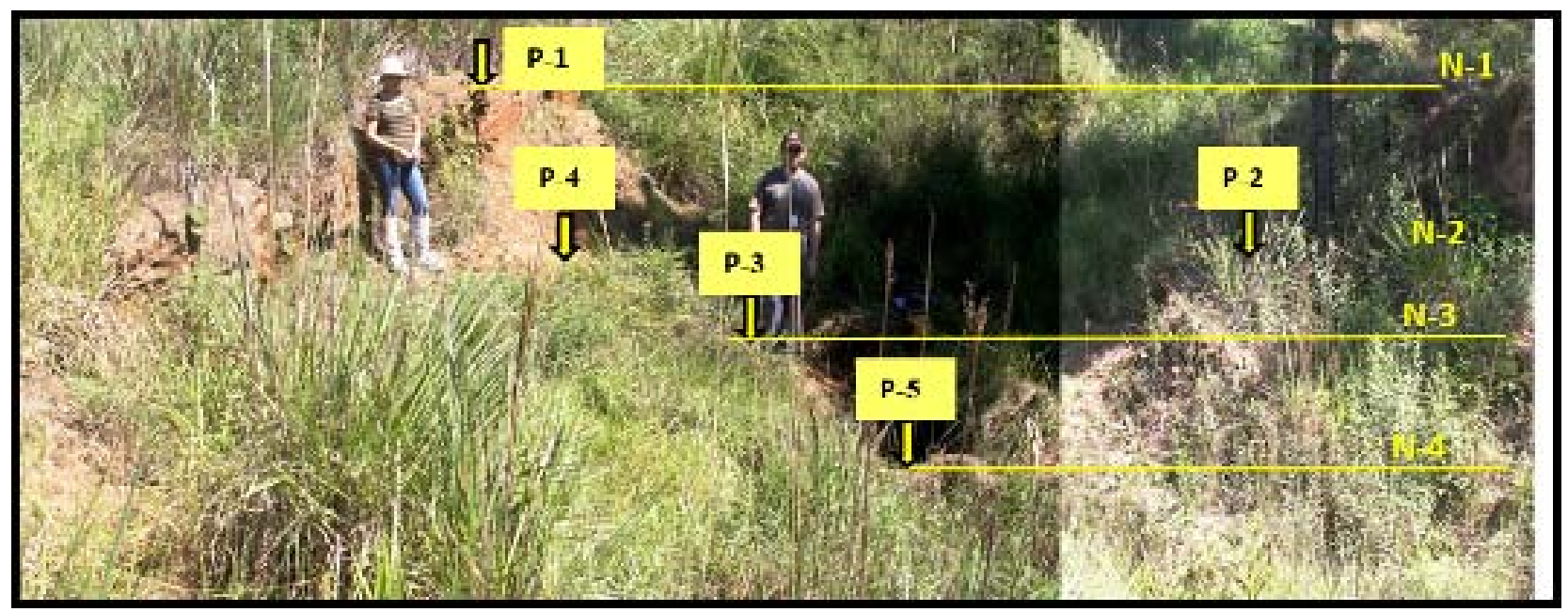

Figura 16: Níveis (N) e perfis (P) estudados. Foto A. M. S. Oliveira, 2013

A análise dos perfis elaborados mostra a existência de vários tipos de depósitos tecnogênicos: depósito construído (DC), depósito induzido (DI), depósito remobilizado (DR) e depósito induzido de preenchimento (DIP), de tal forma que foi possível elaborar uma seção transversal à ravina do Ponto A, conforme a figura 17. Esta figura indica certa complexidade de processos de degradação e agradação; ou seja, o processo de degradação (erosivo) se manifestou em pelo menos quatro níveis, enquanto o processo de agradação que formou o depósito induzido de preenchimento testemunhado apenas do lado direito da ravina é constituído por argila e silte estratificados, indicando deposição em área alagada.

Observa-se também a presença de depósito remobilizado em ambos os lados da ravina, indicando 
Antropoceno - Tecnógeno

pequeno desmoronamento de material do depósito construído na medida em que a erosão progrediu, tendo em vista sua baixa coesão e resistência.

A figura 18 mostra uma hipótese da dinâmica dos processos com base nesta análise.

No Ponto B, foram descritos dois perfis de talude na Ravina 2, conforme ilustrado na figura 19.

A erosão ultrapassou a base do depósito construído e aprofundou na rocha, devido à sua alteração e baixa resistência à erosão. Este processo demonstra o desequilíbrio do balanço hídrico, após a terraplenagem realizada; ou seja, o aumento de escoamento superficial teve energia suficiente para aprofundar a incisão erosiva.

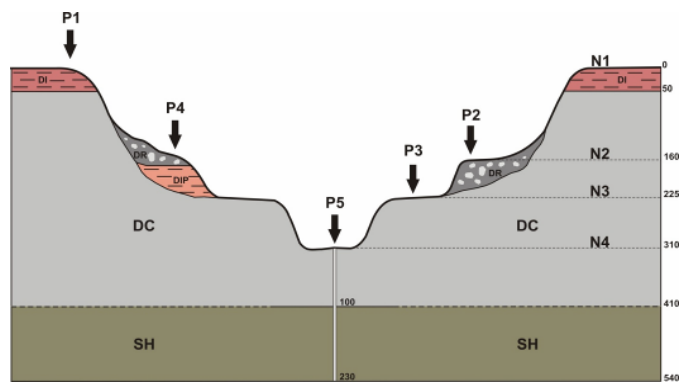

Figura 17: Seção transversal da ravina (R-1) e a disposição dos depósitos. Níveis topográficos - N1 de agradação e N2, 3 e 4 de degradação (erosão). Perfis de análise (P1 a 5). DI - Depósito Induzido; DR - Depósito Retrabalhado; DIP - Depósito Induzido de Preenchimento; DC - Depósito Construído; e SH - Solo Hidromórfico

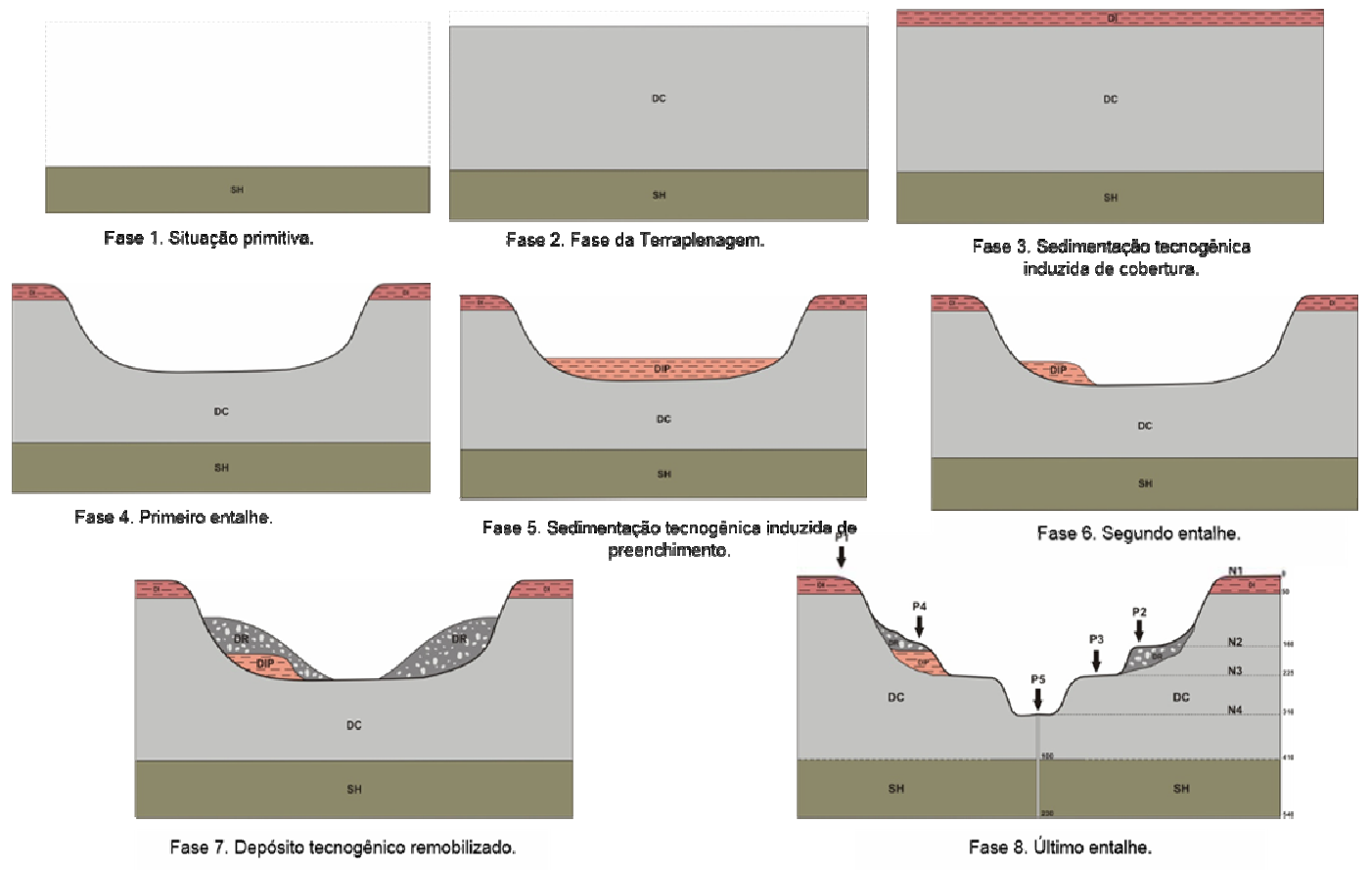

Figura 18: Possível evolução geotecnogênica da R-1. SH - Solo Hidromórfico; DC - Depósito Construído; DI - Depósito Tecnogênico Induzido; DIP Depósito Tecnogênico Induzido de Preenchimento; e DR - Depósito Tecnogênico Remobilizado

Da mesma forma que para o Ponto A, foi elaborada com base nestes perfis a seção da figura 20 e elaborada uma hipótese da evolução dos processos na figura 21.

Nesta hipótese o depósito construído foi depositado, na forma de aterro, logo após a retirada da vegetação junto com o solo existente, que provavelmente era muito raso, sobre a rocha alterada. Posteriormente, deu-se a erosão formando a ravina que aprofundou na rocha alterada, muito suscetível, devido ao aumento do escoamento superficial, provocado pelo desequilíbrio hídrico desencadeado devido ao processo tecnológico de terraplenagem. Em seguida formou-se o depósito induzido de preenchimento, junto ao horizonte $\mathrm{C}$ da ravina, no qual se identificou a presença de um pneu soterrado.

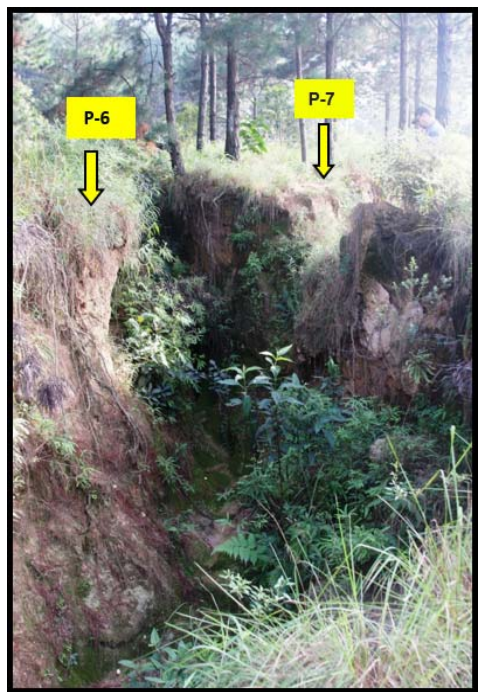

Figura 19: Imagem da ravina (R-2) e localização dos dois perfis descritos. Foto de A. A. Oliveira 2013 
Antropoceno - Tecnógeno

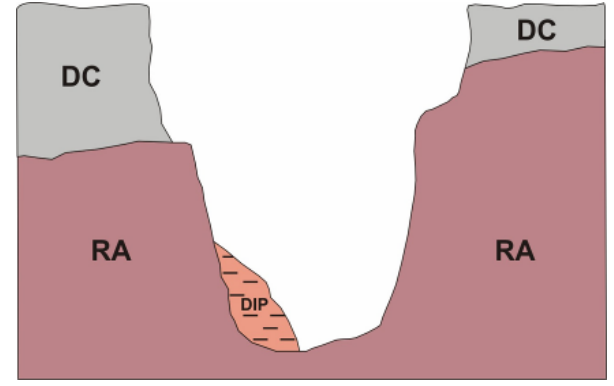

Figura 20: Situação atual da R-2 do Ponto B. DC - Depósito Construído; DIP - Depósito Induzido de Preenchimento; e RA Rocha Alterada

As colunas estratigráficas apresentadas nas figuras 22 e 23 representam a dinâmica geotecnogênica de sedimentação e erosão nos pontos A e B, após a terraplenagem executada na área degradada.

\section{Conclusões}

$\mathrm{Na}$ área degradada predominam os depósitos construídos, espólicos, da terraplenagem. A hipótese elaborada para a dinâmica da erosão, transporte e deposição de sedimentos explica a presença de depósitos remobilizados e induzidos de cobertura e de preenchimento nas ravinas, e também o depósito tecnogênico sobre área de corte a jusante, pouco espesso em rampa com pouca declividade, frequentemente alagada.

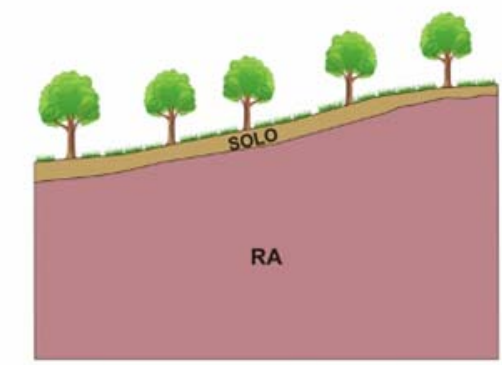

Fase 1. Situaçăo primitiva

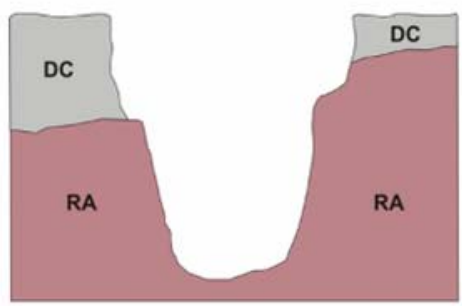

Fase 4. Entalhe, atingiu a RA, devido ao aumento do escoamento
superficial.

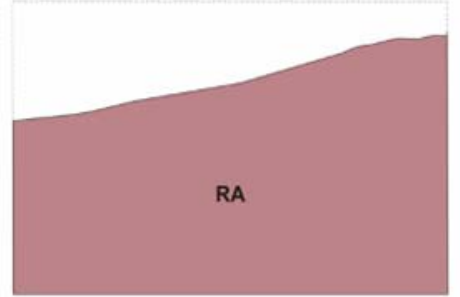

Fase 2. Terraplenagem - corte (retirada do solo raso e da vegetação).

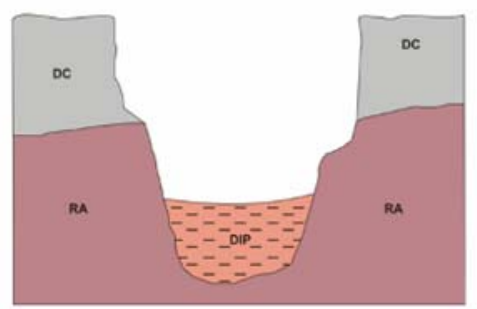

Fase 5. Deposição do DIP.

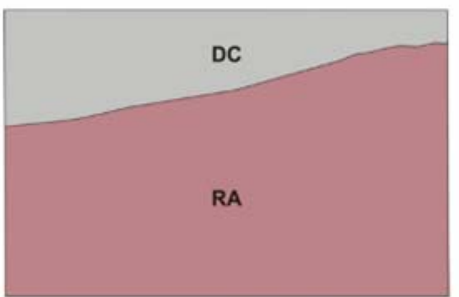

Fase 3. Terraplenagem - aterro.

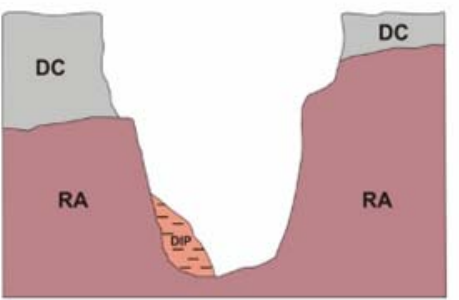

Fase 6. Situação atual.

Figura 21: Possível evolução geotecnogênica da R-2. RA - Rocha Alterada; DC - Depósito Construído; e DIP - Depósito Induzido de Preenchimento

P-A

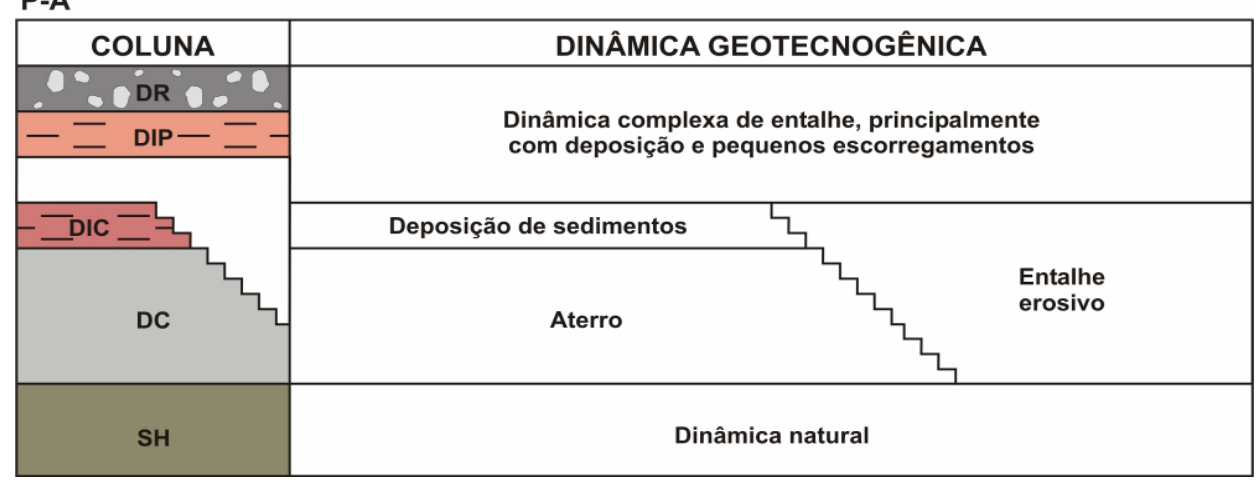

Figura 22: Coluna estratigráfica da P-A. DR - Depósito Remobilizado; DIP - Depósito Induzido de Preenchimento; DIP - Depósito Induzido de Cobertura; DC - Depósito Construído; e SH - Solo Hidromórfico 


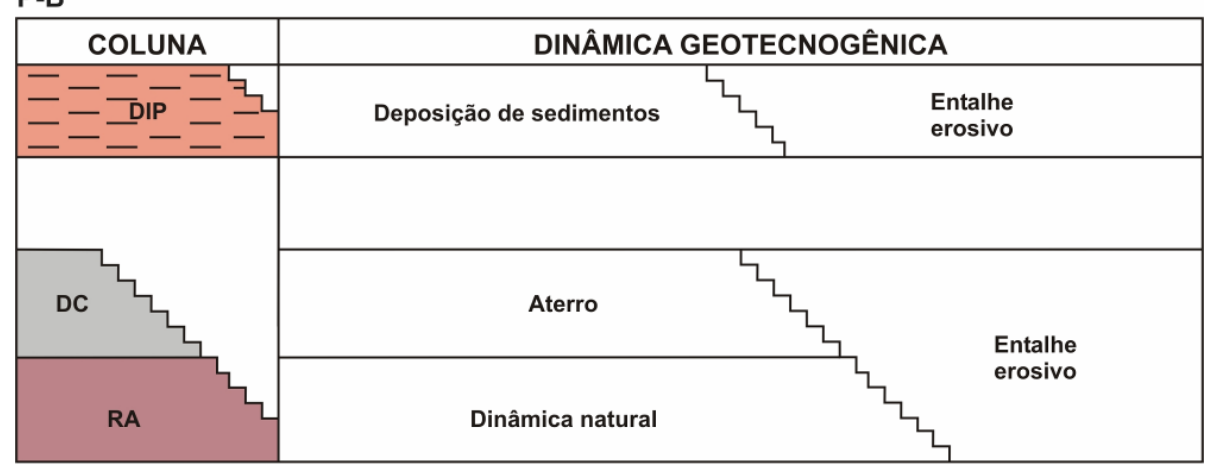

Figura 23: Coluna estratigráfica da P-B. -2. DIP - Depósito Induzido de Preenchimento; DC - Depósito Construído; e RA - Rocha Alterada

Na microbacia, a jusante da área degradada, o extenso depósito de assoreamento pode ter sido formado pelos sedimentos resultantes da primeira ocupação urbana, Jardim Palmira, acrescidos de sedimentos provenientes, em maior quantidade, da implantação do Parque Continental II, sendo em seguida cobertos por sedimentos mais recentes, com pequena contribuição da área degradada.

O levantamento dos depósitos tecnogênicos presentes na área de estudo indica que os processos geotecnogênicos estão com tendência à estabilização, tendo em vista que se encontram entalhados e com início de cobertura vegetal herbácea e gramíneas, especialmente no ponto A.

$\mathrm{O}$ fato de se encontrarem entalhados mostra que as fontes de sedimento cessaram sua produção nos dois pontos A e B. Por se encontrar revegetado, o ponto A indica estabilização do entalhe. A falta de cobertura herbácea e de gramíneas no ponto $B$ deve-se à cobertura de Pinnus, que impede o crescimento de um sub-bosque.

Assim, a análise dos perfis e seções realizada permite que os depósitos tecnogênicos se expressem como indicadores da atual situação da dinâmica dos processos geotecnogênicos desencadeados pela terraplenagem.

Como testemunhos, os depósitos tecnogênicos, por meio da análise dos mesmos perfis, seções e a interpretação dos depósitos, permitem configurar a história evolutiva da paisagem geotecnogênica da área de estudo.

\section{Referências}

Andrade M.R.M. 1999. Cartografia de aptidão para assentamento urbano do município de Guarulhos, SP. Dissertação de Mestrado em Geografia Física na Faculdade de Filosofia Letras e Ciências Humanas da Universidade de São Paulo, 154p.

Andrade M.R.M. 2009. Planejamento ambiental da APA Cabuçu Tanque Grande, Guarulhos, SP. Tese de Doutorado em Geografia Fisica na Faculdade de Filosofia Letras e Ciências Humanas, Universidade de São Paulo, 176p.

Chemekov Y.F. 1983.Technogenic deposits. INQUA Congress, 11, Moscou, Abstrats. v.3. p.62.

Crutzen P.J., Stoermer E.F. 2000. The Anthopocene. IGBP Newsletter, 41:17-18.

Curcio G.R., Lima V. C., Giarola N. F. B. 2004. Antropossolos: proposta de ordem ( $1^{\text {a }}$ aproximação). Colombo: Embrapa Florestas, 49p.
Fanning D.J., Fanning M.C.B. 1989. Soil: morphology, genesis and classification. New York: J. Wiley, 395p.

Nolasco M.C., Oliveira A.M.S. 2000. Tecnogenic actions and record - A proposal of classification. In: Congresso Latinoamericano de Sedimentología, 2, Mar del Plata. Resúmenes 33 p.

Nolasco M.C. 2002. Registros geológicos gerados pelo garimpo. Lavras Diamantinas - Bahia. Tese de Doutorado. Instituto de Geociências, Universidade Federal do Rio Grande do Sul. Porto Alegre. 316p.

Oliveira A.M.S. 1994. Depósitos tecnogênicos e assoreamento de reservatórios: exemplo do reservatório de Capivara, Rio Paranapanema, SP/PR. Tese de Doutorado em Geografia Física na Faculdade de Filosofia, Letras e Ciências Humanas da Universidade de São Paulo. São Paulo, 211p.

Oliveira A.M.S., Brannstrom C., Nolasco M. C., Peloggia A. U. G., Peixoto M. N. O., Coltrinari L. 2005. Tecnógeno: registro da ação geológica do homem. In: Souza C. R. G., Suguio K., Oliveira A. M. S., Oliveira P. E. (eds) Quaternário do Brasil. Ribeirão Preto ed. Holos, 363-378p.

Oliveira, A. M. S. et al. 2009. Bases geoambientais para um sistema de informações ambientais do município de Guarulhos, SP. Relatório do Processo FAPESP: 05/57965-1. 179p.

Peloggia A.U.G. 1996. Delineação e aprofundamento temático da geologia do tecnógeno do município de São Paulo: as consequências geológicas da ação do homem sobre a natureza e as determinações geológicas da ação humana em suas particularidades referentes à precária ocupação urbana, Tese de Doutoramento em Geociências no Instituto de Geociências, Universidade de São Paulo, São Paulo. 162p.

Peloggia A.U.G. 1998. O homem e o ambiente geológico: geologia, sociedade e ocupação urbana no Município de São Paulo. São Paulo: Xamã. 271p.

Peloggia A.U.G.O 1999. Tecnógeno existe? In: Congresso Brasileiro de Geologia de Engenharia. Anais...São Pedro: ABGE, (CDROM). 1999b. São Paulo (SP)

Price S.J.,Ford J. R., Cooper A. H., Neal C.2011. Humans as major geological and geomorphological agents in the Anthropoceni: The significance of artificial grond in Great Britain. Phil. Traus. The Royal Society. v. 369: 1056 - 1084.

Ter-Stepanian G. 1988. Beginning of the Technogene. Bulletin of the International Association of Enginnering Geology, 38:133-142.

Vernadsky W.I. 1945. The Biosphere and the Noosphere. American Scientist, v.33 (1): 12p.

Wilkinson B.N. 2005. Human as geologic agents: a deep time perspective. Geology, 33(3):161-164

Recebido 13 de dezembro de 2013 Aceito 06 de maio de 2014 